\title{
Design and evaluation of carbon fibre-reinforced launch packages with segmented, copper and molybdenum fibre armatures*
}

Marcel Koops, Timo Huijser and Willem Karthaus

TNO PML-Pulse Physics Laboratory, Delft, the Netherlands

\begin{abstract}
Fibre armatures have been studied both dynamically and statically to gain insight in their electrothermal and mechanical behaviour.

In the first part of this paper, the results of launch experiments with single and multi-segment copper and molybdenum fibre armatures integrated in carbon-fibre reinforced launch packages are discussed. The launch experiments with $\mathrm{Cu}$ fibre armatures showed an improved reproducibility and a higher transition velocity. The poor results of the launch experiments with the Mo fibre armatures thus far, are explained with results of armature compliance and resistance measurements.

In the second part, results are presented which are obtained from static experiments in an armature test bed. Using miniature $B$-dot probes and Rogowski coils, the magnetic field diffusion into monobloc and fibre armatures with identical geometry has been studied. The results show a significant difference in diffusion behaviour between the two types of armatures. It appears that the magnetic field diffuses faster into the fibre armature.

The experimental data are compared with the results of calculations of the magnetic field distribution in both armatures based on 2D- and 3Dfinite element computer simulations. The results of the 2D-simulations appear to confirm the measured results for monobloc and fibre armatures only qualitatively. The experimental results obtained with monobloc armatures agree with the results of the 3D-simulations in a quantitative sense.
\end{abstract}

\section{INTRODUCTION}

Arc erosion limits the application of repetitive operating electromagnetic rail accelerators as gun tubes for hypervelocity launch to the lower velocity regime. Transition of the armature interface with the rail from a solid-solid electrical sliding contact to a hybrid one is assumed to be initiated by local melting of the armature. Both electrothermal and frictional heating are heat sources in the melting process and are studied in detail to bring the transition to higher velocities. An improved electrical contact with the rail for a fibre armature in comparison with a monobloc design is expected [1].

Experimental EML research at the Pulse Physics Laboratory is focused on gaining insight in the prevailing mechanisms of the transition process in order to control the creation of stable plasma boundary layers between a solid armature and the rails for the higher velocity regime. Several research objectives have been set in this respect. One goal is to improve the current diffusion in the armature (and the rail)

Manuscript received April 8, 1996.

mailing address: P.O. Box 45, 2280 AA Rijswijk, the Netherlands, visiting address: Schoemakerstraat 97, 2628 VK Delft, the Netherlands, phone: +31152697011 , fax: +31152621268

* applied for patent during electromagnetic launch. By creating a more homogeneous current distribution in the armature, the transition can be postponed. Diffusion depends amongst others on velocity, electromagnetic properties of the armature material, the geometry, structure (e.g. lamination, fibre) and the number of contact spots. One assumption we made years ago [2] was that fibre armatures made of many electrically insulated fibres have better diffusion characteristics. The anisotropic resistive behaviour of this type of armature material is an important reason for its application.

Up to now, the advantageous diffusion characteristics of fibre armatures have only been confirmed on a theoretical basis. An analytical solution to the two-dimensional electrothermal diffusion problem for laminated current collectors was given by Hughes and Young [3] and finite element computer simulations with anisotropic materials were performed by Schoolderman [4], [5].

Launch experiments with electrically insulated fibre armatures have been performed at the Pulse Physics Laboratory since 1987 . Exceptional results have been obtained with respect to arc erosion-free launch in the lower velocity regime [6], [7]. A direct experimental verification of an improved current distribution in fibre armatures, however, has not been presented so far. In this paper, we demonstrate the improved diffusion in fibre materials on the basis of results obtained from experiments performed with an armature test bed.

\section{LAUNCH EXPERIMENTS}

A. Introduction In our pursuit of pushing the transition velocity of fibre armatures to higher values, the structural integrity of the launch package has been one of the problems encountered. The mechanism that caused the premature failure is not yet fully understood. Apparently identical launch experiments showed completely different results with respect to the transition velocity. A relation to the structure of the fibre armature itself is a possibility, since the confinement structure is assumed to have been of adequate strength. Reinforcing the launch package with titanium parts at the expense of an increase in the launch package mass did improve the integrity. As a result, the total action that could be absorbed by the armature and the kinetic energy at transition increased. However, the transition velocity itself could not be increased. Despite several measures to insulate the material, it appeared to be difficult to prevent the titanium parts from taking part in current conduction, resulting in a weakening of the construction. Break-up of the launch package still occurred in some experiments. Next, we decided to redesign the launch package, deleting all the metal reinforcement parts and substituting them with a carbon fibre confinement structure. The new launch package consists of two glass fibre epoxy parts, which are provided with an armature chamber, an armature, and a carbon fibre-wound confinement structure (see Fig. 1). 


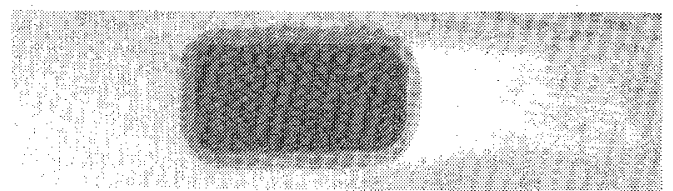

Fig. 1. Carbon fibre-reinforced launch package with integrated arm:ture.

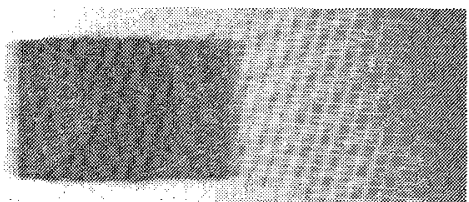

Fig. 2. Armature geometry according to the basic design.
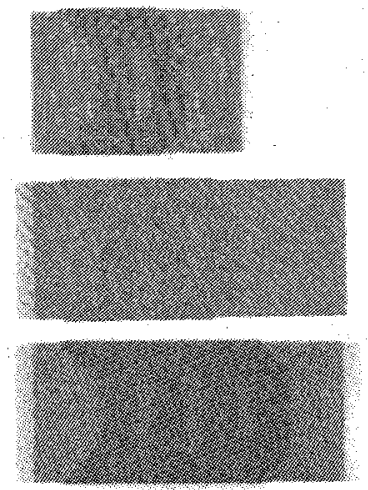

Fig. 3. Geometry of two-segment $\mathrm{Cu}$ and three- and four segment $\mathrm{Mo}$ armatures.

B. Armature designs The basic fibre armature design is shown in Fig. 2. It consists of 11600 insulated $\varnothing 0.1 \mathrm{~mm}$ $\mathrm{Cu}$ wires packed to a density of about $88 \%$. The trailing arm of the fibres is at a 45 degree angle with the rails. Computer simulations have been performed to study the influence of material properties on the velocity at which a part of the armature starts melting. The results have shown that Mo is a better armature material than $\mathrm{Cu}$ when considered from an electrothermal point of view [5]. To take full advantage of a material with a higher resistivity, such as Mo, the armature length must be optimised. Therefore, the geometry of the basic design was changed in order to produce longer armatures. This design consists of multiple armature segments of identical geometry that fit in the glass-fibre epoxy parts (see Fig. 3). Two-segment Cu fibre armatures were tested for comparison with the basic design (same number of fibres). Three- and four-segment Mo fibre armatures were then launched to check our assumptions concerning the potential of Mo as an improved armature material. The Mo fibre armatures used were made of $\varnothing 0.12$ $\mathrm{mm}$ insulated wires packed to a density of about $85 \%$. The three-segment armature had 15300 and the four-segment armature had 20400 Mo fibres.

C. Results The $6.7 \mathrm{MJ}$ electromagnetic launch facility and the $2.4 \mathrm{~m}, 20 \mathrm{~mm}$ square bore rail accelerator have been used for the experiments [7]. Experiments with the new launch packages were conducted at current levels of $300-330 \mathrm{kA}$. A $\mathrm{Cu}$ alloy containing small fractions of zirconium and chromium was used as rail material. The launch packages with basic design and two-segment armatures weighed between 36 and $39 \mathrm{~g}$. Those with three- and four-segment armatures weighed between 53 and $58 \mathrm{~g}$. The typical result
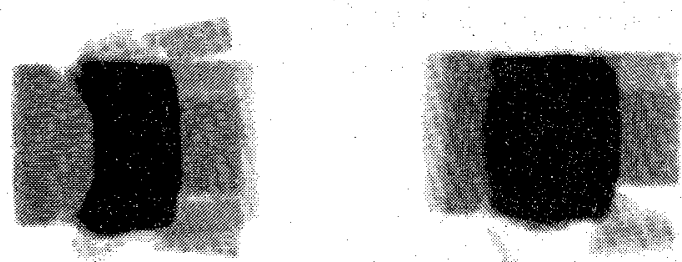

Fig. 4. X-ray shadowgraphs of a launch package with basic design $\mathrm{Cu}$ armature, 10 and $50 \mathrm{~cm}$ in front of the muzzle (top. view).
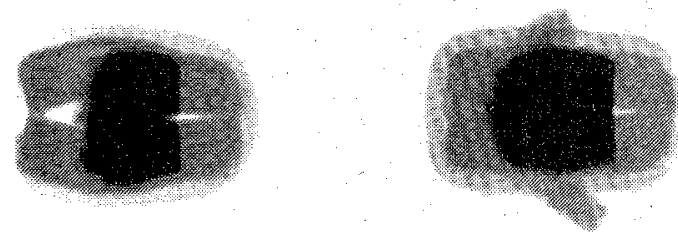

Fig. 5. X-ray shadowgraphs of a launch package with basic design $\mathrm{Cu}$ armature, 10 and $50 \mathrm{~cm}$ in front of the muzzle (side view).

obtained with the redesigned launch package provided with a basic design $\mathrm{Cu}$ fibre armature was acceleration to $1150 \mathrm{~m} / \mathrm{s}$, while maintaining good, solid-solid, non-arcing electrical contact with the rails. At these velocities, arcing of the armatures started at the positive rail followed by arcing at the negative rail. In the non-arcing contact area, only small scratches caused by the sliding of the fibre tips of the armature over the rail surface were visible under a microscope (i.e. mechanical wear of the armature). A superficial deposit of launch package materials - the result of transition further down the bore - could easily be wiped off. Arc erosion of the rail surface is visible in the area of transition. These experiments reproduced better than before and the transition process occurred more gradually. Sometimes, lower transition velocities were obtained at lower maximum currents. Orthogonal X-ray shadowgraphs of a complete launch package with an armature of the basic design, 10 and $50 \mathrm{~cm}$ in front of the muzzle, are shown in Figs. 4 and $5 \quad(v=1250$ $\mathrm{m} / \mathrm{s}$ ). The package, including the armature, remained nearly intact and the presence of liquid material from the armature surface is visible. These photo's show the deformation of the launch package after it leaves the muzzle, indicating the large internal stresses. The original geometry is restored in flight, showing the elasticity of the carbon fibre-wound confinement structure. A representative set of load current and muzzle voltage data for this series of experiments is presented in Fig. 6. Characteristic of an arc erosion-free launch experiment is a low voltage drop across the rail-armature boundary layers, indicating a good electrical sliding contact. At transition, a gradual, stepwise increase of the muzzle voltage from a few volts to a value typical for plasma armatures $(150 \mathrm{~V})$ occurs. The visual effects on the rail surface confirm the measured data. A continuous velocity profile, obtained with a VISAR, is shown in Fig. 7 together with velocity data deduced from B-dot probe signals and X-ray shadowgraphs. Due to plasma blow-by, the VISAR signal is lost at the moment of transition. A Figure of Merit (FOM) for this type of armature is shown in Fig. 8 (FOM is kinetic energy divided by the energy dissipated in the armature).

The launch experiments with the two-segment $\mathrm{Cu}$ fibre armatures showed results comparable to those with the basic 


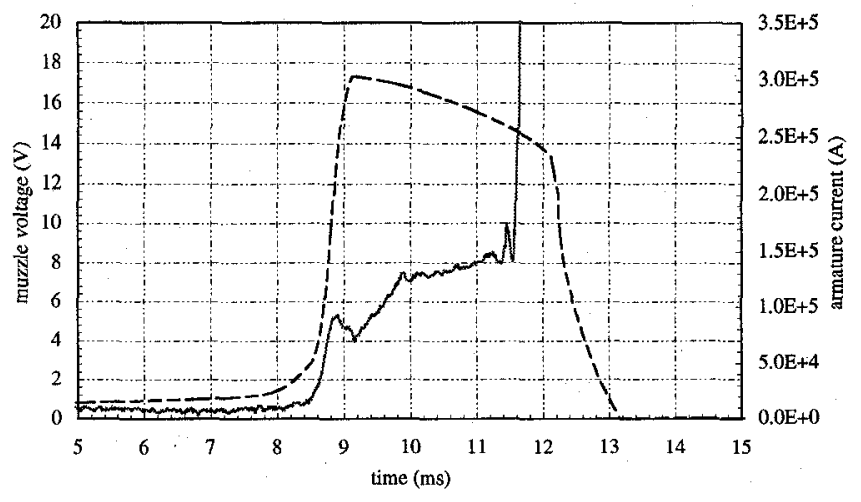

Fig. 6. Armature current (dashed) and muzzle voltage.

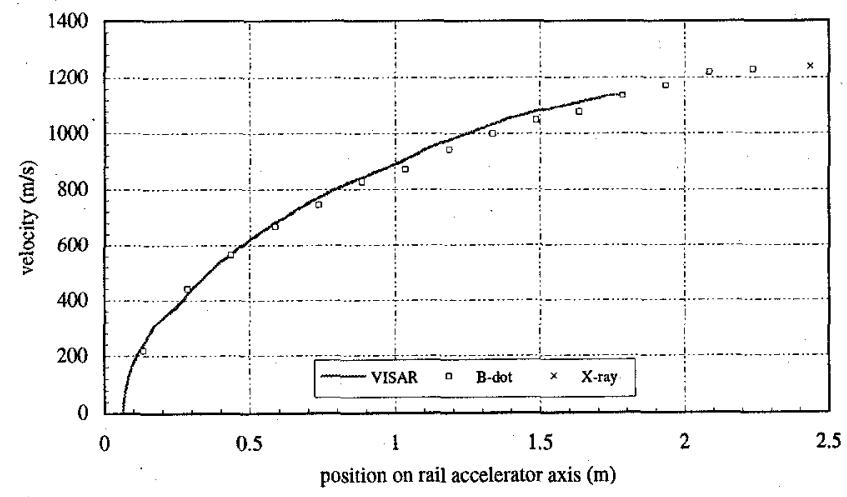

Fig. 7. velocity profile as a function of the armature position.

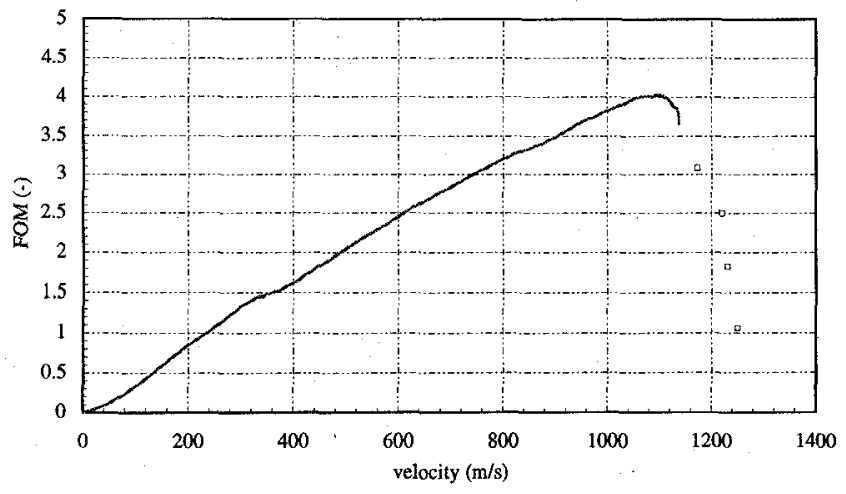

Fig. 8. Velocity-dependency of the FOM for a basic design armature.

design (see Fig. 9). The results with both the three- and foursegment Mo fibre armatures showed an unexpected early transition to a hybrid armature. From Fig. 10, it appears that a larger part of the fibre armature is missing or is compressed to a higher density at the forward edge. An apparent armature resistance (voltage across the armature divided by the armature current) of about $70 \mu \Omega$ was measured just before the start of

TABLE I

TYPICAL RESULTS OF LAUNCH EXPERIMENTS WITH FIBRE ARMATURES

\begin{tabular}{llccr}
\hline $\begin{array}{c}\text { armature } \\
\text { material }\end{array}$ & \# of segments & $\begin{array}{c}\text { maximum } \\
\text { current } \\
(\mathrm{kA})\end{array}$ & $\begin{array}{c}\text { action at } \\
\text { transition } \\
\left(\mathrm{A}^{2} \mathrm{~s}\right)\end{array}$ & $\begin{array}{c}\text { transition } \\
\text { velocity } \\
(\mathrm{m} / \mathrm{s})\end{array}$ \\
\hline $\mathrm{Cu}$ & 1 (basic design) & 321 & $2.6 .10^{8}$ & 1137 \\
$\mathrm{Cu}$ & 2 & 316 & $2.3 .10^{8}$ & 1173 \\
$\mathrm{Mo}$ & 3 & 303 & $1.1 .10^{8}$ & 400 \\
$\mathrm{Mo}$ & 4 & 307 & $1.7 .10^{8}$ & 550 \\
\hline
\end{tabular}

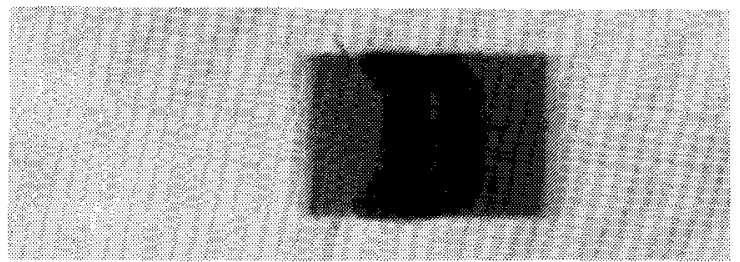

Fig. 9. X-ray shadowgraph $10 \mathrm{~cm}$ in front of the muzzle (2-segment $\mathrm{Cu})$.

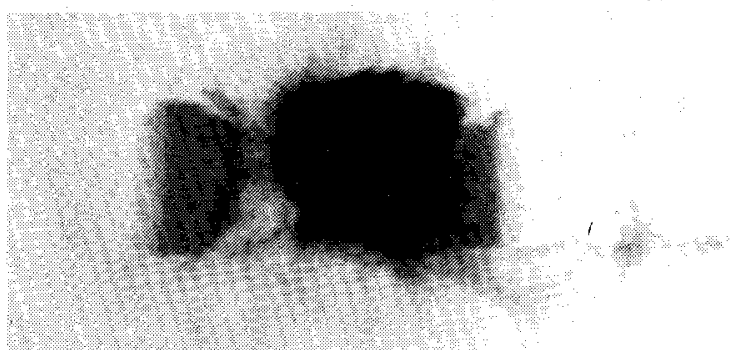

Fig. 10. X-ray shadowgraph $10 \mathrm{~cm}$ in front of the muzzle (4-segment Mo).

the launch process when a homogeneous current of $25 \mathrm{kA}$ flows through the armature. This value is rather high compared with the typical $10 \mu \Omega$ obtained for $\mathrm{Cu}$ armatures with only $75 \%$ of the number of fibres. The early transition obtained with the Mo armatures is assumed to be related to this high initial armature resistance. Table I summarises the results of launch experiments with fibre armatures. They represent typical measured values. The transition velocity was deduced from VISAR measurements.

\section{MECHANICAL BEHAVIOUR OF FIBRE ARMATURES}

From the results described in the previous section, it is clear that other effects than those related to the electrothermal properties of the armatures are involved. Due to the complex manufacturing procedure of fibre armatures, the mechanical behaviour is difficult to understand. In this paper, the results of compliance measurements are presented. The set-up has been described in [8]. The armature compliance is expected to play an important role in establishing the desired preload force on the electrical contact between the armature and the rail. Fig. 11 shows the compression of a $\mathrm{Cu}$ fibre armature as a function of the preload force. Fig. 12 shows the same for a three-segment Mo fibre armature. It appears that the stressstrain behaviour for both fibre armatures shows a relaxation effect: when the compression is sustained at a fixed value, the preload force is reduced with time (on a minutes time scale). After decompression, the armature is deformed, permanently. With every next compression cycle, the force-compression curve appears to have shifted to lower force values, while the slope holds the same value, approximately. Table II lists the results of compliance measurements for different types of $\mathrm{Cu}$ and Mo armatures. The results show that the compliance of a

TABLE II

RESULTS OF COMPLIANCE MEASUREMENTS OF FIBRE ARMATURES INTEGRATED IN CARBON-FIBRE REINFORCED LAUNCH PACKAGES

\begin{tabular}{llcr}
\hline $\begin{array}{c}\text { armature } \\
\text { material }\end{array}$ & \# of segments & \# of fibres & $\begin{array}{c}\text { compliance } \\
(\mathrm{m} / \mathrm{N})\end{array}$ \\
\hline $\mathrm{Cu}$ & 1 (basic design) & 11600 & $9.3 \cdot 10^{-9}$ \\
$\mathrm{Cu}$ & 2 & 11600 & $10 \cdot 10^{-9}$ \\
$\mathrm{Mo}$ & 2 & 10800 & $6.8 \cdot 10^{-9}$ \\
$\mathrm{Mo}$ & 3 & 15300 & $10.2 \cdot 10^{-9}$ \\
$\mathrm{Mo}$ & 4 & 20400 & $8.5 \cdot 10^{-9}$ \\
\hline
\end{tabular}


three- or four-segment Mo armature is comparable to the compliance of a two-segment $\mathrm{Cu}$ armature, which could imply that the compliance does not strictly depend on fibre material but also on geometry and launch package design. It appears that the confinement structure influences the internal stress distribution in the fibre armature to a higher extent than expected.

Figs. 11 and 12 also show the DC armature resistance as a function of preload force measured in the same set-up. The curve for the $\mathrm{Cu}$ fibre armature can be reproduced quite well from electrical contact theory by assuming a plastic contact spot at each fibre tip in the higher contact force range [9], [10]. At the lower end, the existence of elastic contact spots resulting in a higher constriction resistance cannot explain the observed armature resistance. Apparently, a number of fibres do not make proper electrical contact at low contact force. For Mo, an armature resistance of about $70 \mu \Omega$ is measured at a contact force of $4 \mathrm{kN}$, whereas a value of about $15 \mu \Omega$ is calculated. This is probably caused by the fact that only a limited number of fibres make proper contact in the Mo fibre armature over the considered contact force range. A contact resistance of $70 \mu \Omega$ can only be calculated by assuming that about $40 \%$ of the fibres make proper contact (due to increased bulk resistance). The argument is augmented by inspection of the load bearing contact area at the rail surface under a microscope. Indentations of the individual fibres are not uniform over the nominal contact area. By measuring the $\mathrm{DC}$ armature resistance inside the rail accelerator at maximum bolt torque, a value of $9 \mu \Omega$ was found for $\mathrm{Cu}$ and a value of $70 \mu \Omega$ was found for $\mathrm{Mo}$, in agreement with the values found during launch experiments.

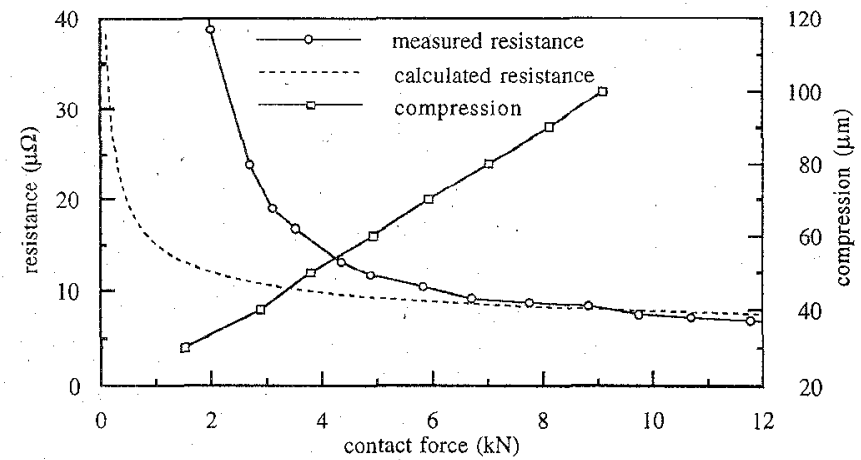

Fig. 11. Compliance and armature resistance of a $\mathrm{Cu}$ armature as a function of a static preload force.

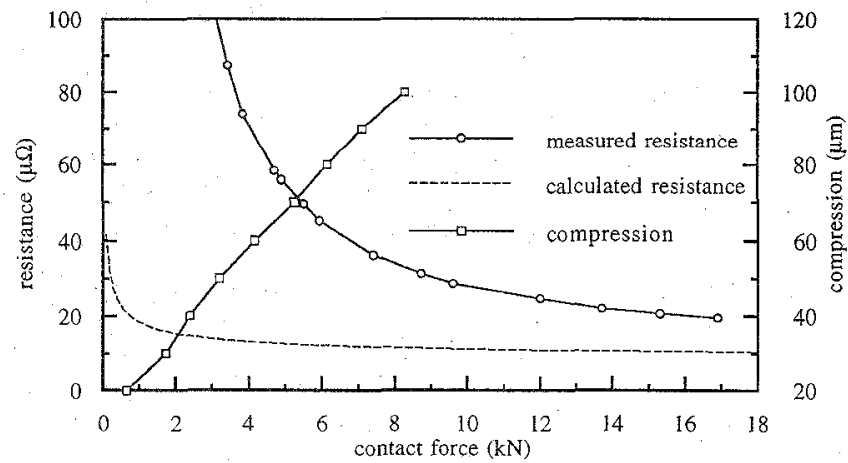

Fig. 12. Compliance and armature resistance of a Mo armature as a function of a static preload force.

\section{ARMATURE TEST BED STATIC EXPERIMENTS}

A. Introduction The armature test bed is a $50 \mathrm{~cm}$ long rail accelerator that is optimised for static testing of armatures and diagnostics [11]. It resembles our $2.4 \mathrm{~m}$ rail accelerator as close as possible. The armature test bed is connected to a 400 $\mathrm{kJ}$ capacitor bank. In this paper, the results of measurements of electromagnetic properties will be used to validate theoretical models of armatures. Although the static behaviour of an armature differs fundamentally from an armature that is accelerated (a.o, velocity skin effect), a quantitative understanding of static results may indicate the potential of different armature concepts and materials.

$B$. Diagnostics Diffusion of the magnetic field into the armature occurs mainly from the trailing to the forward edge of the armature (+x direction in Fig. 13). To study this process, special miniature magnetic field sensors, voltage probes and Rogowski coils were constructed [11]. The magnetic field sensor is essentially an array of small B-dot probes placed closely together. The magnetic field in the $z$ direction was chosen to be measured in order to be able to compare the experimental results with $2 \mathrm{D}$-computer simulations of fibre armatures at stand-still. Since it is not possible to measure the magnetic field or current density inside the armature directly, a compromise had to be made. Symmetry considerations made us decide to create a gap inside the armature to host the diagnostics. Inside the gap, the curl of the magnetic field is zero. Therefore, several field derivatives are balanced. Since the field must be continuous at the gap-armature boundary and the gap size is small compared with the armature length, we assumed that $B_{z}(\mathrm{x})$ would closely resemble the field inside the armature (at least resemble the shape of the field distribution). The magnetic field obtained by integration of the B-dot signals could then be used to deduce the current density profile $J_{y}(x)$ inside the armature.

C. Experimental results To check the validity of the assumptions made in the previous sections, a few proof-ofprinciple experiments were carried out (see [11]). The positive results of the proof-of-principle experiments with solid armatures gave us confidence to continue with some of our $\mathrm{Cu}$ fibre armatures (basic design). For comparison, a $\mathrm{Cu}$ monobloc armature with an identical geometry was included in the series (see Fig. 13). The same contact force was applied in both cases (equal to initial conditions in launch experiments). Therefore, a lower contact resistance for the fibre armature may be assumed due to a higher number of contact spots. A better diffusion due to contact resistance would be in favour of the monobloc armature. Consequently, when a faster diffusion into the fibre armature is measured, it can be ascribed to its anisotropic resistive behaviour. For these experiments, an array of 12 B-dot probes was made (dimensions: 40 turns "race track" type; $4 \times 1 \mathrm{~mm}, 1.5 \mathrm{~mm}$ apart). B-dot \#1 and \#2 are located between the trailing arms;

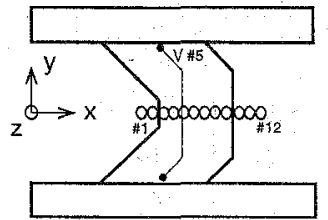

Fig. 13. Position of the magnetic field probes. 


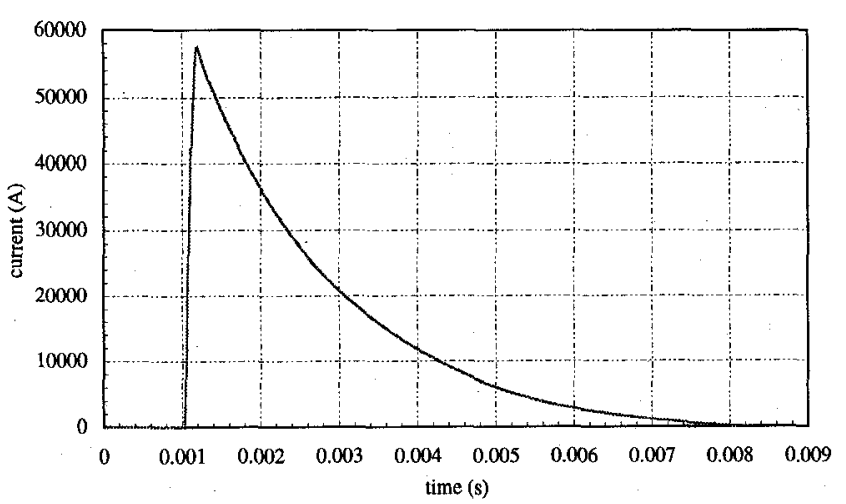

Fig. 14. Current profile I(t) applied to armature test bed experiments.

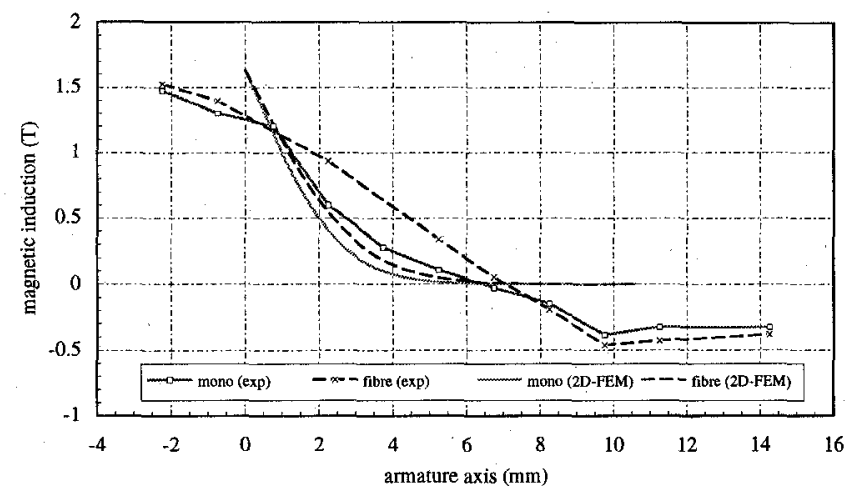

Fig. 15. The measured and calculated magnetic induction $B_{Z}(x)$ at $t=1.2 \mathrm{~ms}$ for a monobloc and a fibre armature.

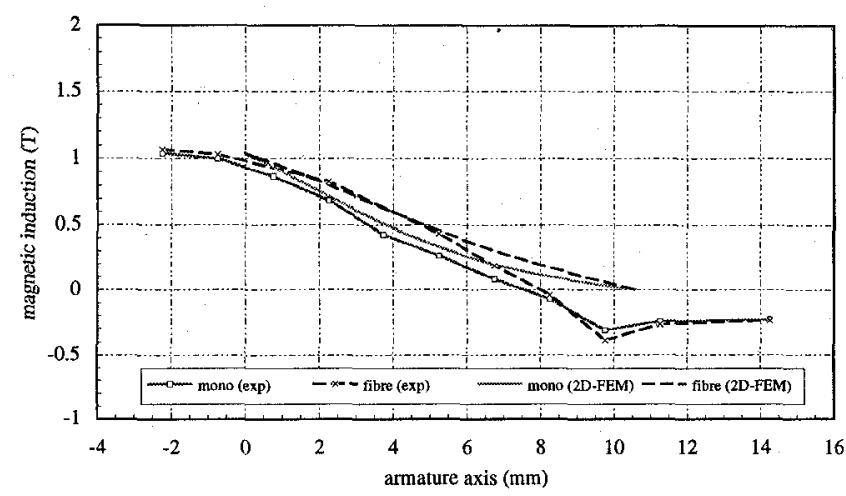

Fig. 16. The measured and calculated magnetic induction $B_{Z}(x)$ at $t=2.0 \mathrm{~ms}$ for a monobloc and a fibre armature.

$\# 10, \# 11$ and \#12 are in front of the armature. The others are within the geometry boundary. Fig. 14 shows the current pulse used in the experiments. Figs. 15 and 16 show the magnetic field profiles for $\mathrm{Cu}$ monobloc and $\mathrm{Cu}$ fibre armatures at different points in time (1.2 and $2.0 \mathrm{~ms}$, respectively). The curves labelled "mono (exp)" show the experimental result for the monobloc armature. The field is curved initially, indicating a higher current density at the trailing edge of the armature. After $2.0 \mathrm{~ms}$ the curvature of the field profile is reduced and a more uniform current density is established. The $\mathrm{Cu}$ fibre armature shows a different behaviour (labelled "fibre (exp)"). At $1.2 \mathrm{~ms}$, a straight line is obtained for the field profile between the trailing $(0 \mathrm{~mm})$ and forward edge $(10.6 \mathrm{~mm})$ of the armature. For every later time step, the values for the fibre armature are larger than those for the monobloc. As expected, the difference between both profiles is reduced in time. The lines cross at $8 \mathrm{~mm}$

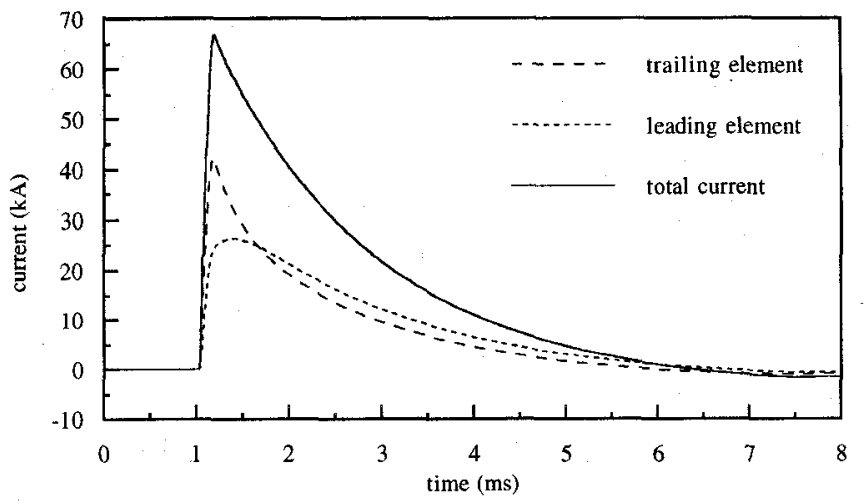

Fig. 17. Current distribution in a two-segment $\mathrm{Cu}$ fibre armature.

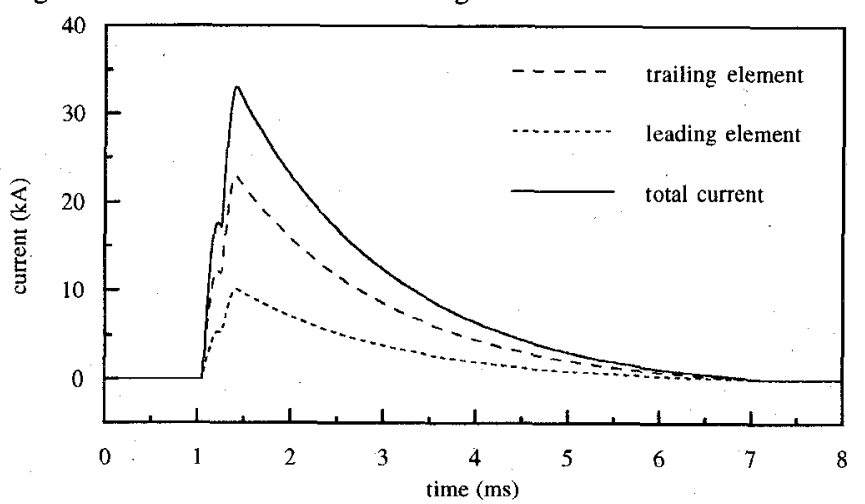

Fig. 18. Current distribution in a two-segment Mo fibre armature.

approximately and the magnetic field at the forward edge is in the opposite direction of the field at the trailing edge for the full duration of the current pulse.

Figs. 17 and 18 show the results of test bed experiments with two-segment $\mathrm{Cu}$ and Mo fibre armatures. Miniature Rogowski coils were used to measure the current through the trailing and leading segment, separately. The total armature current is also shown. Fig. 17 shows the relatively good current distribution for the $\mathrm{Cu}$ fibre armature (compared with monobloc and taking the rail resistance into account). The effect of current diffusion into the armature is evident. For the Mo armature, the current in the trailing and the current in the leading segment were expected to be equal, approximately. Although diffusion is completed quickly, this experiment shows a maldistribution of the current in the two-segment Mo armature. It is assumed again that this is caused by an improper electrical contact between the armature and the rails.

D. Discussion The experimental results presented in Figs. 15 and 16 have been compared with the results of 2D simulations of monobloc and fibre armatures (labelled "mono (2D-FEM)" and "fibre (2D-FEM)"). The calculated magnetic field has been multiplied by a factor $L / \mu_{0}$ to account for the different inductance gradient $\mathrm{L}^{\prime}$ of the armature test bed compared with its value in the $2 \mathrm{D}$ representation. Up to 2.0 $\mathrm{ms}$, the curvature of the calculated magnetic field profiles is stronger than for the experimental ones. After $2.0 \mathrm{~ms}$, the simulated diffusion process is completed, approximately. Two-dimensional codes for solving the magnetic diffusion equation have certain restrictions. The calculation of the magnetic field in the forward part of the armature is not completely correct due to the assumed boundary conditions at the front of the armature $\left(\mathrm{B}_{\mathrm{Z}}=0\right.$ in this case). The calculations 
with the 2D-code cannot explain the increased current density at the front end of the monobloc armature. A 3D electromagnetic code is necessary to simulate these effects in this region. Therefore, the experimental results have also been compared with the results of simulations performed with the 3D-code MEGA. For direct comparison, the B-dot coils have been incorporated in the simulation model. Fig. 19 shows that the experimental and calculated voltage induced in B-dot \#1 match perfectly. Fig. 20 shows the magnetic field profiles inside the gap at maximum current $(t=1.2 \mathrm{~ms})$. Both curves are in close agreement. The figure also shows a calculated magnetic field profile for an armature without the gap. The deviations imply that the current density inside the armature cannot be reconstructed from these field measurements as expected (neither absolute value nor profile) since the measured magnetic field profile does not resemble the one inside the monobloc armature. Thus, only qualitative statements can be made concerning the magnetic field diffusion into different types of armatures using this method unless the gap is made unpractically small.

\section{CONCLUSIONS}

From the experiments with the redesigned launch packages, it can be concluded that an improved confinement structure resulted in a higher transition velocity. The transition process is not under control yet. An explanation for erratic transition behaviour of the fibre armatures in a series of comparable experiments might be slight differences in the initial experimental conditions such as the preload force on the electrical contact between the armature and the rail from one experiment to the other. Thus far, the results of experiments with Mo fibre armatures do not meet the expectations from theoretical considerations and from the early results with nonoptimised, non-insulated Mo fibre armatures [7]. The poor results are ascribed to the high initial resistance of Mo fibre armatures. It appears that electrical contact theory can predict the armature resistance for $\mathrm{Cu}$ fibre armatures in the high contact force range but cannot predict the armature resistance for Mo fibre armatures. An improper electrical contact with the rail is assumed, probably caused by differences in internal stress distribution in $\mathrm{Cu}$ and $\mathrm{Mo}$ fibre armatures resulting in a non-uniform contact force across the contact area.

Experimental evidence of a faster diffusion process in electrically insulated fibre armatures has been obtained by comparing results of magnetic field measurements inside monobloc and fibre armatures, showing that at least from this point of view fibre armatures perform better than monobloc armatures. The experimental results have been compared with 2D simulations of a monobloc and a fibre armature and 3D simulations of a monobloc armature. Although the general trend in the measurements is reproduced by the 2D-results, only the 3D-results match the experimental data adequately. The 3D-results also show that no quantitative information concerning the magnetic field and current distribution inside the armature can be obtained from the magnetic field diffusion measurements.

\section{ACKNOWLEDGEMENT}

The authors are grateful to Dr. W.J. Kolkert for his encouragement and comments on the manuscript. The discussions with Arnold Schoolderman concerning the

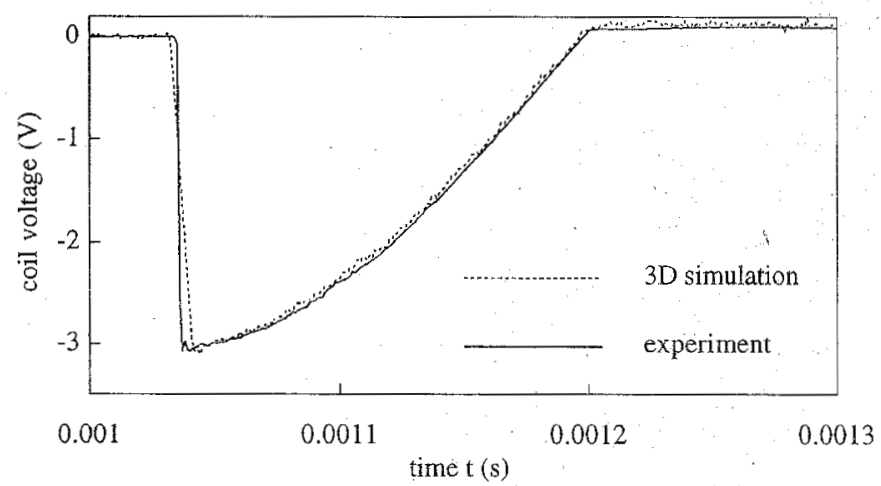

Fig. 19. Measured and calculated voltage induced in B-dot \#1.

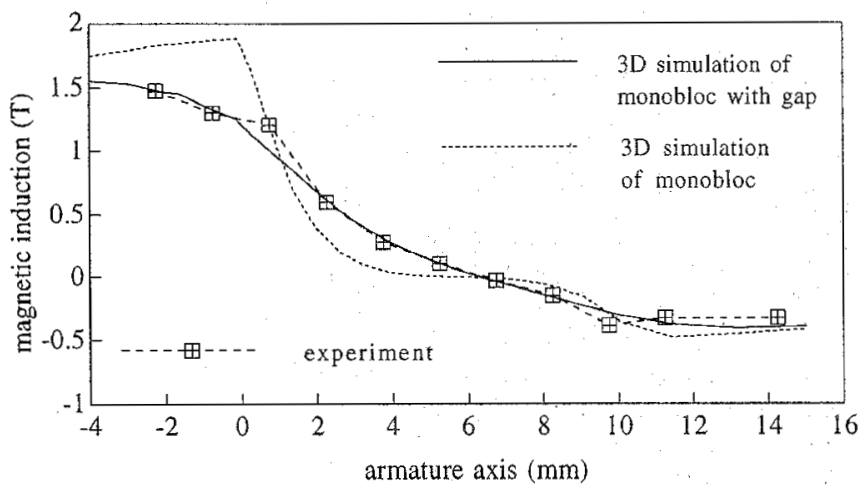

Fig. 20. Comparison of the measured magnetic induction $B_{Z}(x)$ at $t=1.2 \mathrm{~ms}$ with results of $3 \mathrm{D}$ simulations for a $\mathrm{Cu}$ monobloc armature.

interpretation of the experimental data and his efforts for performing the ET-code and MEGA simulations are much appreciated. The authors wish to acknowledge the contributions of Thijs van Leeuwen, Erik Olthof and Jan Starrenburg for the fabrication of the sensors and performing the experiments.

\section{REFERENCES}

[1] G.L. Ferrentino and W.J. Kolkert, "On the design of an integrated metal armature and sabot for railguns," IEEE Trans. Magn. 22 (1986), $1470-1474$.

[2] W. Karthaus, W.J. Kolkert, E. Tuinman, and W.A. de Zeeuw, "Further experimental results obtained with the $6.7 \mathrm{MJ}$ repetitive EM rail launcher at PML-Pulse Physics," Procs. 2nd Eur. Symp. on EMT Techn., 27 - 29 Sept 1989, ISL; France.

[3] W.F. Hughes and Young. F.J., "Diffusion skin effects in ultrahigh velocity laminated current collectors," Wear 78 (1982), 171 - 178.

[4] A.J.Schoolderman, "Two-dimensional electrothermal modelling of multi-fibre solid brush armatures;" Procs. 4th Eur. Symp. on EML Techn., May 2 - 6 1993, Celle, Germany.

[5] A.J. Schoolderman, "Performance predictions for electromagnetic launching with multi-fibre solid brush armatures and resistively layered rail accelerators," IEEE Trans. Magn. 31 (1995), 651 - 656.

[6] W. Karthaus, W.A. de Zeeuw, and W.J. Kolkert, "On the design and testing of solid armatures for rail accelerator applications," IEEE Trans. Magn. 27 (1991), 308 - 313.

[7]. W. Karthaus and M. Koops, "Results of experiments performed with multi-fibre solid brush armatures," Procs. 4th Eur. Symp. on EML Techn., May 2 - 6 1993, Celle, Germany.

[8] T. Huijser, M. Koops, and W. Karthaus, "Aspects of mechanical behaviour of fibre armatures," Procs. 13th Meeting of the ELA, October 9 -11, 1995, Austin Tx. (USA).

[9] D. Kublmann-Wilsdorf, "Theoretical speed and current density limits for different types of electrical brushes," IEEE Trans. Magn. 20 (1984), 340-343.

[10] R. Holm, "Electrical Contacts," 4th edition, Springer Verlag 1981 (Reprint form 1958 ed.).

[11] M. Koops and W. Karthaus, "Test bed for the evaluation of solid armature concepts," Procs. 5th Eur. Symp. on EML Techn., April 10 -13, 1995, Toulouse, France 